\title{
Children's novel NN compounding in Swedish diary data: function and form
}

\author{
Maria Rosenberg $^{1}$ (D) Ingmarie Mellenius $^{1}$
}

Received: 15 May 2017 / Accepted: 5 April 2018 / Published online: 14 May 2018

(C) The Author(s) 2018

\begin{abstract}
This study explores formal aspects and functions of 420 novel noun-noun (NN) compounds in diary data from three Swedish children (1;9-6;11). With regard to form, the data show that the children's compounds respect target head order, allow for a small amount of internal inflection, and, in more than half of the cases where a liaison form is required, are properly formed. Most of the compounds concatenate two nouns (without the presence of liaison forms), as is the general case for Swedish NN compounds. With regard to function, the data permit us to distinguish three main functions of the coinages: I. Novel compound instead of established term, II. Novel compound for novel category, and III. Novel compound for specific entity. Type I involves attempts to target conventional compounds by relying either on perceptual or functional features or on recalled semantic, phonological, and/or morphological cues. Type II is innovative compounding par excellence: detailed discriminations and fantasy concepts are named. Type III divides into anaphoric and deictic uses as well as what we call appropriation, i.e. naming a specific entity. Types II and III are functions displayed by novel compounds in general. In conclusion, the three children seem to master the central facets of NN compounds, formally and functionally. Furthermore, compound production can constitute a simple and efficient means for young children to maximize and build more structure into their lexicon.
\end{abstract}

Keywords Novel compounds · Combined concepts · Naming · Child language · Spontaneous production $\cdot$ Swedish

\section{Introduction}

Word-formation is a multifaceted task involving both linguistic abilities (phonology, morphology, semantics) and cognitive abilities (e.g. categorization, perception, cre-

M. Rosenberg

maria.rosenberg@umu.se

1 Department of Language Studies, Umeå University, 90187 Umeå, Sweden 
ativity). In language development, the production and comprehension of complex words involve several problems to overcome. ${ }^{1}$ Mastering word-formation processes results in a mental lexicon with more structure and content, which facilitates the learner's task to retain, retrieve and learn lexical items (Tschichold and ten Hacken 2015).

Studies on word-formation in language acquisition are rare, depending partly on the methodological problems involved in gathering data, such as biases in elicitation or instruction tasks (Elsen and Schlipphak 2015). Considering that longitudinal recordings contain few innovative word-formations, it is difficult to gather coinages through any other method than careful diary notes (Elsen and Schlipphak 2015). ${ }^{2}$ Nicoladis (2007) and Berman (2009) both reviewed the field of compound acquisition, and found that much research is concentrated on the comprehension of novel compounds, predominantly in English. Given that speech production and perception are asymmetric phenomena (Remez 2015), many of the recent findings on children's language comprehension do not extend to production (Naigles and Bavin 2015).

In Swedish, compounding is the most common way to construct complex words. Spoken Swedish is full of compounds and compounds are frequent words in children's daily life, with noun-noun (NN) compounding showing high input frequency. As Dressler et al. (2003) suggest, the frequency of a phenomenon in the input is probably more important for children's lexical expansion than its productivity, where a productive morphological process can be defined as being both available, through the language system, and profitable, in that it has been or can be used to produce a high number of new words (cf. Corbin 1987; Bauer 2001). Hence, children acquiring Swedish are continuously exposed to positive evidence of compounds, and their active word stock contains many compounds. As to their formal aspects, Swedish NN compounds are right-headed, written as one word, pronounced with a particular prosodic contour, and can exhibit liaison forms. The prosodic contour of Swedish NN compounds has high cue validity in that it signals that the compound constitutes one word, standing for one object (cf. Koester 2014 for German and Roll 2015 for Swedish who show that prosody plays a central role in adult compound processing).

The present study investigates the formal aspects and the functions of three Swedish children's novel NN compounds, such as matbok 'food-book' for a cookbook. It is based on diary data of spontaneous innovative word-formation produced between ages one to six. The first research question addresses how the children deal with compound structure, such as head order, internal inflection, and liaison forms. Comprised under this research question is also their possible establishment of constituent families (e.g. water in water-fall/-play/-gun). Clearly, the main interest lies in the second research question: what functions do the children's novel NN compounds

\footnotetext{
${ }^{1}$ This study situates complex words within a lexeme-based morphological approach, where the lexeme is the abstract, uninflected counterpart of the syntactically contextualised word-form, endowed with phonological form, meaning, and grammatical category (cf. e.g. Matthews 1974; Fradin 2003; Booij 2005). A compound is, accordingly, a complex lexeme, generated by morphological rules (cf. Corbin 1992).

${ }^{2}$ In addition, using spontaneous production data drawn from familiar settings to complement experimentally-based findings is considered important for a broader understanding of children's linguistic capacity (Bryant 2015; Fletcher and O'Toole 2016).
} 
display in relation to the functions generally displayed by novel compounding? Our hypothesis is that children coin novel NN compounds that mirror functions characterizing novel compounds in general. But, since their lexicon and world knowledge are still being acquired, their novel NN compounds may deviate from target use. Two opposing views serve as a starting-point for our analysis of the functions. According to Downing (1977), speakers use novel compounds as a naming device or as a deictic device. Clark (e.g. 2016), however, advances that adults and children coin new compounds to fill lexical gaps and for communicative purposes.

The study is organized as follows. The theoretical background is presented in Sect. 2. Section 3 accounts for the data and Sect. 4 deals with the qualitative analysis of formal properties and functions displayed by the children's compounds. Finally, concluding remarks are given in Sect. 5.

\section{Theoretical background}

A key feature of language development is that although linguistic forms might emerge during the preschool years, they take a long time to master (Berman 2015). Psycholinguistic and usage-based theories of language acquisition highlight the role of frequency of occurrence in the input (Berman 2009). Statistical-learning approaches, likewise, assume young children implicitly identify patterns and group features that co-occur in the input by using processes that interplay with focused attention, perception, and prior experience (Thiessen and Erickson 2015). French-learning infants are proposed to use statistical information to store word candidates (i.e. words and nonwords) in a protolexicon, but these sound forms are not always paired with a meaning (Ngon et al. 2013). This top-down view, where vaguely specified linguistic information at one level enables learning at another level, contrasts to the bottom-up view of children gradually building a lexicon, starting with familiar words. Elbers' (e.g. $1995)$ "output-as-input hypothesis" takes a complementary stance by positing that the child's linguistic analysis operates primarily on her own production, taken as input for reanalysis. Studies focussing on the child's output thus tell us more about what is actually acquired than studies mainly concerned with input. Children's language errors (e.g. overextensions and overregularization) constitute potential empirical evidence for the hypothesis (Elbers 1995). Furthermore, the hypothesis also explains how young children may grasp form (morphotax and/or phonology) before meaning (Dressler et al. 2003).

Semenza and Mondini (2010) emphasize the study of word-formation in aphasia as a crucial way to integrate models of neuropsychological and theoretical linguistics. By studying aphasic errors due to failures in morphological processing, different evidence has been provided. For example, morphological information has been found to be independent from the retrieval of phonological form (e.g. the compound effect: in case of retrieval problems, compounds replace compounds, and single words replace single words) (Semenza and Mondini 2010).

Furthermore, with regard to adult compound processing, multiple-route models advocate flexible and cooperative lexical processing of morphological cuesinformation is drawn both from the compound and its constituents (e.g. Kuperman 
et al. 2009). Neuroscientific approaches propose that both semantic and lexical properties of compounds and compound constituents intervene in all stages of word processing (Marelli and Luzzatti 2012). Libben (2014) emphasizes that new compounds are mostly formed through a partial analogy process by exchanging one constituent (usually the modifier) of an existing compound resulting in larger compound families. The lexical processing system is designed to maximize opportunity for activation, not to maximize efficiency. Hence, pre- and postlexical decomposition as well as constituent and whole-word access are advantageous for meaning activation (Libben 2014).

In light of these complementary approaches, our study assumes that both the child's input and output are fundamental sources for language development. We also hypothesize that the findings above have implications for children's processing of word-formation in that they permit us to assume that children process compounds by several routes.

\subsection{Acquisition of compounding}

Children learn compounds as chunks (Berman 2009; Dressler et al. 2010). By clustering similar compounds together, they start to understand compound structure by focussing on the head constituent as the fixed entity that has different possible relations to the modifier: in this way, a constituent family becomes established, and an abstract pattern develops (Krott et al. 2009). Elsen and Schlipphak (2015) point out that language acquisition is a gradual process, and that the acquisition of wordformation patterns proceeds in steps. Young children attend to complex words both as unanalyzed wholes and as consisting of parts, which they later begin to combine analogically, ending up with word-formation rules closer and closer to the target.

Given a mental model in which a compound links both to a whole word representation and to the constituents' position-bound representations (e.g. Libben 2014), children's compound acquisition involves, prior to the building of such links, the ability to detect compound structure (Krott and Nicoladis 2005). Children analyze new compounds in analogy with previous knowledge about compound meanings and forms, leaning on paradigms and general organizing tendencies (Dressler et al. 2003; Krott 2009; Clark 2016). Within as well as across languages, input frequency (token and type) and constituent family size (cf. Krott et al. 2009) influence what compound types emerge early.

Based on longitudinal data of children's language use up to age three from several languages, Dressler et al. (2003) relate the emergence of morphological processing to lexical development. Children proceed, with interindividual variation, from premorphology, where some morphologically complex words are stored and extragrammatical processes are used, to protomorphology, which involves generalizations over complex words and creative morphology. In the data of compound use by two German-speaking children (ages 1;3 to 3;0), NN compounds emerge simultaneously with noun and verb inflection and diminutives. Prototypically, these compounds are subordinate and endocentric and without linking elements (Dressler et al. 2010). ${ }^{3}$

\footnotetext{
$335 \%$ and $41 \%$, respectively, of all noun lemmas were compounds in the two children's input; in their output 19\% and 33\% of all noun lemmas were compounds (Dressler et al. 2010: 334).
} 
Mellenius (1997) is the only elaborated study of Swedish compound acquisition. From age 2, Swedish children begin to produce compounds. Most of her findings are experimentally based, and they suggest the following developmental path: (i) compound stress is mastered around age 2; (ii) children below age 3 rely mainly on NN compounding; (iii) the right-hand head position is established around age 3;6; (iv) liaison forms are mastered gradually during the preschool years; (v) the interpretation of novel compounds is mastered the last, after age 6 .

\subsection{Children's comprehension vs. production of compounds}

It is generally assumed that comprehension precedes production in language acquisition (e.g. Berman 2009). When it comes to compounding, the situation is less clear, considering that few studies have investigated compound production and comprehension within the same children (Nicoladis 2007). Krott (2009) points out an inconsistency in previous research. For Hebrew and French-speaking children, comprehension precedes production (Krott and Nicoladis 2005; Nicoladis 2007). Hebrew compounds exhibit complex morphology and are infrequent in spoken input. Consequently, comprehension emerges around age three and production emerges around age five (Clark and Berman 1987; Berman 2009). By contrast, in English and Swedish, where compounds, in particular NN compounds, are highly frequent, children have, as mentioned, been found to produce novel compounds around age two (e.g. Becker 1994; Mellenius 1997) and to understand subcategorization by compounding around age three (e.g. Clark et al. 1985).

However, other findings propose that this development is slower and gradual, and they question that children understand subcategorization at age 3 (cf. Krott 2009). To identify the head of the compound implies knowing which category is being talked about (e.g. hat in sunhat). To identify the relation between head and modifier is a more challenging task. Occasionally, interpretative cues can be drawn from the context. Otherwise, children lean mainly on two sources: experience of linguistic structure and lexical knowledge (Mellenius 1997). According to Krott et al. (2009), family size and frequency affect comprehension. Children have a better understanding of relations in familiar compounds that belong to larger constituent families, and young children's understanding of novel NN compounds relies on individual knowledge of compound constituents (Krott et al. 2009).

The available evidence can thus imply either that production and comprehension develop closely together or that children produce NN compounds before they fully understand their subcategorizing role so that production paves the way for full comprehension of compound meaning (Nicoladis 2007). The latter assumption echoes Elbers' (1995) output-as-input hypothesis. In fact, as both Nicoladis (2007) and Dressler et al. (2010) claim, the point in development when children begin to create compounds marks the understanding of the basics of NN compounds: decomposition into head and modifier.

\subsection{Explanations for novel compounding}

Downing (1977) posits two motivations behind a speaker's decision to use a novel compound instead of an established item or a syntactic phrase. The first use, the 
naming device (e.g. garbage-man), expresses a generic relationship and implies that a name-worthy category exists. The second use, the deictic device (e.g. apple-juice seat), picks out a temporarily name-worthy entity in order to facilitate identification. Deictic compounds have low lexicalization potential, and are in this respect more similar to proper names than to class names. Still, Downing is aware of the gradual nature of these functions: "Indeed, it is probably the case that most compounds start out as deictic ones; but only those based on permanent, classificatorily relevant relationships survive" (1977: 840).

Clark (e.g. 1981, 2015, 2016) claims that children's and adults' coinages fill lexical gaps, viz. the Lexical Gap Hypothesis (LGH). In addition, Clark assumes that novel word-formation has a communicative function: "children, like adults, coin new words to communicate more precisely what they mean" (Clark 1981: 10). Children's coinages involve a choice of word forms that, according to Clark, depends on principles such as transparency of meaning, simplicity in form, productivity of the wordformation pattern, conventionality, and contrast. The principles of contrast and conventionality work in tandem and imply that children's coinages are legitimate if they contrast in meaning with conventional words. Still, Clark claims, many innovations by children violate these principles and are thus illegitimate. As word learning proceeds, children will cease conveying meaning by coinages because these are preempted by conventional terms.

Brekle (1986) investigates pragmatic aspects among 3,400 German nominal ad hoc compounds (mainly written text). Following Clark's LGH, Brekle (1986) posits that all ad hoc compounds imply lexical gaps, insofar as there is no word with identical meaning (albeit his analysis is a bit confusing on that point). Two variants of gaps are discerned: (i) reification, i.e. bringing something into being - the compound makes an abstract concept real; (ii) stylistic gap, i.e. instead of an established alternative, a novel compound is used (which would be illegitimate in Clark's terminology). Brekle (1986) also singles out two referential uses (cf. Downing 1977): (i) the quasipronominal use which establishes referential identity between two expressions (e.g. the election-crew of Clinton $>$ the Clinton-crew); (ii) the deictic use which facilitates the identification of a referent in a given context (cf. Downing's 1977 apple-juiceseat).

Elbers (1988) questions the LGH by instead identifying two types of compounds among children: compelled or preferred. Children resort to compelled compounds when "no adequate syntax and/or no appropriate lexical items are available" (Elbers 1988: 594). Alternatively, children sometimes prefer to coin compounds, aiming at conceptual rather than communicative precision, although established terms are accessible to them (reflecting Brekle's stylistic gap; contradicting Clarks' idea of preemption). Preferred compounds are motivated by an urge to name a new concept on the spot in a precise way (Elbers 1988). ${ }^{4}$ Windsor (1993) and Becker (1994) confirm Elbers' assumption that children produce novel compounds for other reasons than filling gaps, such as redundant compounds and novel compounds that are produced ulterior to established terms for the same referent. Dressler et al. (2010) likewise

\footnotetext{
4Elbers' (1988) view is shared by Costello (2002), who poses that conceptual representation, not communicative precision, drives adults to construct novel compounds.
} 
question Clark's principles that are linked to her LGH. Their data show that the principles are too strong regarding synonymy blocking because children sometimes use variant compounds for the same object.

Mellenius (1997) points out that it is difficult to define a lexical gap and to verify that coinages are used to fill gaps. With an aim similar to Elbers, Mellenius lists six interacting motivations of varying status for children's lexical creativity: (i) the conventional word for the concept is not known to the child (Clark's illegitimate formation); (ii) a conventional word does not exist (Clark's legitimate formation); (iii) play - by being put into language, the fantasy world comes into existence (reflecting Brekle's reification); (iv) to contrast several items of a similar type; (v) the pleasure of finding le mot juste (cf. Elbers preferred compounds); (vi) naming brings things into the realm of known items.

As is clear from above, there is empirical evidence against the LGH, which furthermore seems to allude to the metaphor of a mental dictionary containing blanks for missing words. Libben specifies that this metaphor is not the best description of our mind; compounds are not "entities that exist outside the mind [and, once acquired,] end up "inside the mind"' (2014: 12). We agree with Elbers (1988) and Mellenius (1997) that lexical gaps are not the driving force for children's novel compounding, but we find their different criteria hard to apply empirically. In particular, it is problematic to judge when and whether children prefer, or are compelled by language, to coin innovations.

\section{Data}

Our data of 420 novel NN compounds were collected through diary notes from three children. All children were monolingual in Swedish and typically developing. S and $\mathrm{H}$, daughters of one of the authors, were two younger sisters with one older brother and sister. E, son of the other author, had two older brothers and, towards the end of the study period, a younger sister. $S$ was followed from age 2;7 to 6;11 (96 compounds), $\mathrm{H}$ was followed from age 1;9 to 5;3 (120 compounds), and $\mathrm{E}$ was followed from age $3 ; 9$ to $6 ; 6$ (204 compounds).

Shortcomings of diary data are that the original notes cannot be double-checked, features of input and phonetics are not obtained, and the documentation can be biased (Christensen 2010: 24-26). Since, in our case, the registration was pre-biased towards novel word-formation, the data do not include much of the children's production of conventional compounds, nor do they pretend to capture the entire stock of the children's novel compounds. Nevertheless, diary data present several advantages. They constitute an easy way to collect data in natural and unconstrained settings at any hour of the day. Moreover, they can provide valuable qualitative aspects of the child's language production to complement quantitative data obtained by other methods, and they can capture items (viz. novel word-formation) that would not be sufficiently frequent in audio/video recordings (Christensen 2010). For the purpose of the present study, we find it important to be able to analyze three data sets on novel word-formation to detect possible common patterns. That the diarist knows the child very well, as in our case, gives a solid foundation for a detailed semantic analysis 
of the child's intended meaning, supported by the accompanying contextual information. Still, to analyze diary data is a matter of subjective interpretation: we strive to be as explicit and careful as possible to make our interpretations transparent and open for reinterpretation.

The diaries were kept with one goal in mind: to write down non-established word-formation spontaneously produced by the children in different daily situations. They include direct quotations of novel compounds, written down when they were first overheard, and accompanied by information about situation, external worldknowledge, intended meaning and interpretation, other people's utterances, etc. On several occasions, the children provided a tenable explanation of the compound's intended meaning (e.g. ekorremelon, E 4;8, 'squirrel-melon', "one feeds squirrels with that"). The three diaries varied as to size and age span, but their overall composition was similar and highly concordant. The children's pronunciation was normalized to regular Swedish spelling, but reflected formal deviations as captured. Their age was rendered as year and month (e.g. 3;9). The handwritten original versions were transferred to computer files, where one novel word-formation corresponded to one entry (type/token ratio almost $100 \%, 418 / 420) .^{5}$

In the present study, only novel compounds, combining two nouns and exhibiting the characteristic compound stress pattern of Swedish were included. The motivation for our strict criterion to include only novel compounds (vs. established compounds) was the general view that only lexical innovations are proof of productive wordformation because the child could have stored or imitated all other complex lexemes (e.g. Elsen and Schlipphak 2015). Becker (1994), as well as Mellenius (1997), point out that children's use of innovations might be underestimated because of the difficulty in deciding whether the child imitates or re-invents a conventional compound when producing it. Some novel compounds in our data involved only a slight deviation of form in one of the constituents, for example, in the liaison form, compared to the established target. The way we see it, any formal deviation indicates an active coining.

\section{Analysis of formal aspects and functions}

Our analysis of the novel NN compounds produced by three Swedish children divides into two parts. The first part accounts for the compounds' formal aspects, and the second part deals with their functions.

\subsection{Formal aspects of the novel compounds}

In what follows, we analyze the three Swedish children's novel compounds with regard to their formal aspects, namely headedness, internal inflection and liaison forms. Constituent families are also examined in this context.

\footnotetext{
${ }^{5}$ Four compounds were counted as two types. H $(2 ; 9)$ and E $(4 ; 6)$ both produced klädnypare 'clothes-pincher' instead of the established klädnypa 'clothes-pin'. E $(3 ; 11)$ produced the two variants $\operatorname{grod}_{\phi}$ mamman 'frog-mommy-DEF' (i.e. correct target form with deletion of the final vowel of the first constituent) and grodamamman, 'frog-mommy-DEF' (simply concatenating the two nouns).
} 


\subsubsection{Headedness}

The novel compounds in our data respect correct head-modifier order, confirming what has been shown for children whether acquiring English, (Clark et al. 1985), Hebrew (Clark and Berman 1987), Swedish (Mellenius 1997), or German (Dressler et al. 2010). Of the 420 novel compounds, there are only two clear examples of reversed head-modifier order, both of which were produced by the same child, as in (1):

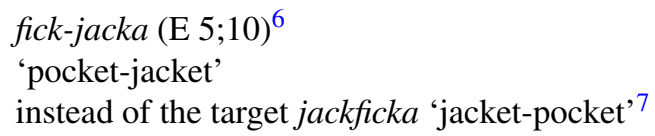

\subsubsection{Internal inflection}

Monolingual English children occasionally allow internal plural (regular and irregular) in compounds (Nicoladis 2005). In the view of Nicoladis (2005), they learn to avoid internal inflection, presumably in analogy with already acquired compounds. In our data, internal inflections are found on 12 occasions (only among the two girls, $\mathrm{S}$ and $\mathrm{H}$, and mostly at age three) and comprise both regular (2) and irregular (3) plurals:

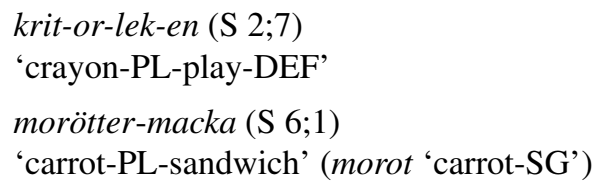

There are also two cases of an internal definite singular, one is given in (4):

$$
\begin{aligned}
& \text { jobb-et-väg-en }(\mathrm{S} 2 ; 7) \\
& \text { 'work-SG.DEF-road-DEF' }
\end{aligned}
$$

In sum, our data speak in favour of children's use of internal inflection as a marginal phenomenon just as it is in conventional Swedish compounds.

\subsubsection{Liaison forms}

Preschool children gradually learn to insert linking elements if their language requires such elements. Different liaison forms occur occasionally in Swedish compounds. The final vowel of the first constituent is sometimes deleted (e.g. hjärta 'heart', but

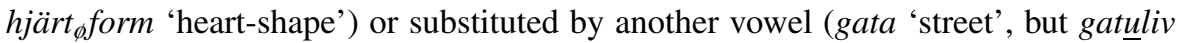
'street-life'). There can also be an insertion of a vowel (kung 'king', but kungakrona

\footnotetext{
${ }^{6}$ The numbered examples are provided with child and age specifications. Counter to regular spelling, the compounds are split up into lexemes, linking elements and inflections. Plurals involving stem modifications are not split up.

${ }^{7}$ However, the child wanted a thing from the pocket of his vinterjacka 'winter-jacket', and also produced vinterficka 'winter-pocket' on the same occasion. Since vinterjackficka 'winter-jacket-pocket', the precise target, is a rather complex concept, this probably provoked a bit of confusion for the child.
} 
'king's crown') or a linking -s- between the two constituents (e.g. liv 'life' but livstid 'life-time'). Synchronically, no comprehensive rules account for the application of liaison forms. This means that children have few cues to lean on here, except perhaps constituent families. For example, a child can become aware of the fact that hjärt'heart-', not hjärta 'heart', is the target form to insert as the first constituent in a compound. Our data do indeed contain cases where the same child coined at least two compounds within the same month containing the same N1 in its correct liaison form (fluga 'fly' vs. flug-):

$$
\begin{aligned}
& \text { flug }_{\phi} \text {-hål (S 3;3) } \\
& \text { 'fly-hole' } \\
& \text { flug }_{\phi} \text {-hus (S 3;3) } \\
& \text { 'fly-house' }
\end{aligned}
$$

However, we also found the already mentioned case (see f.n. 5), where the boy alternated between regular deletion or not of N1's final vowel within the same month:

$$
\begin{aligned}
& \operatorname{grod}_{\not} \text {-mamma-n }(\mathrm{E} 3 ; 11) \\
& \text { 'frog-mommy-DEF' } \\
& \text { groda-mamma-n }(\mathrm{E} 3 ; 11) \\
& \text { 'frog-mommy-DEF' }
\end{aligned}
$$

In total, around one third of the novel compounds $(146,35 \%)$ in our data require some kind of liaison form in order to be regular. In the majority of these cases ( 82 compounds), the children conformed to the target use and either inserted a linking $-s$ or deleted the final vowel of the first constituent. In the remaining non-target cases (64 compounds), the children either concatenated two objects without any linking elements as in ex. (8) (49 compounds) or used a non-target-like liaison form (15 com-

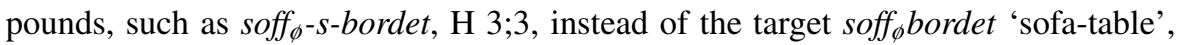
soffa 'sofa'). Considering the fact that the majority of established NN compounds in Swedish conform to a purely concatenative pattern (i.e. no liaison forms are involved), the children's use of liaison forms reflects this frequency effect. Overall, Swedish liaison forms seem to be tricky to master before age six, confirming Mellenius' (1997) experimental data of Swedish liaison forms in language acquisition.

To sum up, there is no clear relation to age in our data concerning the application of internal inflection and linking elements. Target-like forms emerged just before or around age three, but non-target-like forms were still used by all three children up to age six. Sometimes the same child varied between different forms of the N1 constituent. Hence, similar to Dressler et al. (2010) we cannot confirm Clark's (e.g. 2015) principles of transparency of meaning, simplicity in form and contrast in relation to the children's choice of word forms.

\subsubsection{Constituent families}

The tension view of creativity (Weisberg 1999) stipulates that maximum creativity in language production occurs when we are neither too familiar nor too unfamiliar with a domain. Lynott and Keane (2005), in examining the effects of familiarity on 
adult production of novel NN compounds, confirm the tension view of creativity. Since children are in the progress of becoming familiar with both environment and language, they could thus be assumed to exhibit lexical creativity. A way to analyze familiarity effects in our data is to sort the lexical items according to word family, a dynamic concept evolving with lexical growth. Word family is defined as "a base word and all its derived and inflected forms that can be understood by a learner without having to learn each form separately" (Bauer and Nation 1993: 253).

A sorting of the children's novel compounds based on N1 and N2 reveals that the children use familiar nouns as modifiers and heads in their compounding: several nouns of central importance for their daily life reoccurred (around 33\% of the N1s and $38 \%$ of the N2s). Among all three children, vatten 'water', either as N1 or N2, was the most commonly used constituent (13 compounds). Other nouns occurring nearly ten times among all children were bil 'car', kläder 'clothes', mamma 'mommy', and väg 'road'. Most of the novel compounds were situated in familiar domains, especially the domains of food, clothes, vehicles, and animals. Clark (1981) posits that children's innovations predominate in domains where they have few available terms. In contrast, Becker claims that "there were more innovations in categories in which there were more well-established lexical items" (1994: 206); a claim confirmed by our data.

The fact that the children used familiar constituents and situated their compounds in familiar domains supports the assumption that compound production could precede full compound comprehension; since in comprehension, unknown constituents and compound meanings might be challenging for the child. What is more, by producing novel compounds children can develop knowledge about compound structure and constituent properties (in line with Elbers' output-as-input hypothesis and multi-route processing of compounds, as accounted for in Sect. 2).

\subsection{Functions of the novel compounds}

Table 1 summarizes our classification of the displayed functions. Given the multifaceted nature and use of NN compounds, the numbers should be seen as indications. In addition, the functions should be considered as being of a gradual nature. ${ }^{8}$ Three main functions (I-III), represented both within and between the children, are singled out, with two sub-functions each.

Function I most clearly manifests that the children's lexicon is under construction: the compounds stick out because they depart from the conventional target. Functions II and III are commonly displayed by novel compounds in general (Downing 1977), and the children can be assumed to extract these functions from their input.

\subsubsection{Novel compound instead of established term}

Two sub-types, relying on different explanations as to their formation, were discerned: (i) variant or approximation; (ii) overspecification.

\footnotetext{
${ }^{8}$ According to Rainer (2003), a gradual phenomenon can be hypothesized to be of a semantic-pragmatic nature.
} 
Table 1 Functions of novel compounds produced by three Swedish children

\begin{tabular}{|c|c|c|c|c|c|}
\hline NN Compounds & $\begin{array}{l}S \\
96\end{array}$ & $\begin{array}{l}H \\
120\end{array}$ & $\begin{array}{l}E \\
204\end{array}$ & $\begin{array}{l}n \\
420\end{array}$ & $\begin{array}{l}\% \\
100\end{array}$ \\
\hline I. Novel compound instead of established term & 22 & 42 & 70 & 134 & 32 \\
\hline i. Variant or approximation & 18 & 31 & 53 & 102 & \\
\hline ii. Overspecification & 4 & 11 & 17 & 32 & \\
\hline II. Novel compound for novel category & 32 & 37 & 76 & 145 & 35 \\
\hline i. Detailed discrimination & 25 & 19 & 31 & 75 & \\
\hline ii. Reification & 7 & 18 & 45 & 70 & \\
\hline III. Novel compound for specific entity & 42 & 41 & 58 & 141 & 34 \\
\hline i. Anaphoric and deictic & 28 & 24 & 45 & 97 & \\
\hline ii. Appropriation & 14 & 17 & 13 & 44 & \\
\hline
\end{tabular}

(i) Variant or approximation

Sometimes the children create an alternative to an established compound by relying on functional or perceptual features, available in context or recalled, of the object to be named:

(10) $\quad$ koss $_{\phi}$-rumm-et (E 3;10)

'cow-room-DEF'

instead of ladugård 'byre/cow barn'

(11) horn-hatt (E 5;5)

'horn-hat'

instead of vikingahjälm 'Viking-helmet'

The children's compounds can also be similar to the target compounds in different respects. The children seem to have a trace of the established compound and try to recreate it. In most of these approximations, they replace one constituent of the established compound by a semantically and phonologically similar term:

(12) ägg-burk-en (H 2;1)

'egg-bowl-DEF'

instead of äggkopp 'eggcup'

(13) $\quad k l a ̈ d_{\phi}$-nyp-are (H 2;9)

'clothes-pincher'

instead of klädnypa 'clothes-pin/peg'

(14) is-korv (S 3;6)

'ice-sausage'

instead of isterband 'lard-strips', i.e. a type of sausage 
födelse-dag-s-klapp ( $\mathrm{H} 4 ; 1)$

'birth-day-s-clap/pat'

instead of födelsedagspresent 'birth-day-s-present', but note that julklapp 'Christmas- clap/pat' is the regular word for Christmas present

(16) hår-nål (E 4;6)

'hair-nail'

instead of hårspänne 'hair-pin' i.e. 'bobby pin'

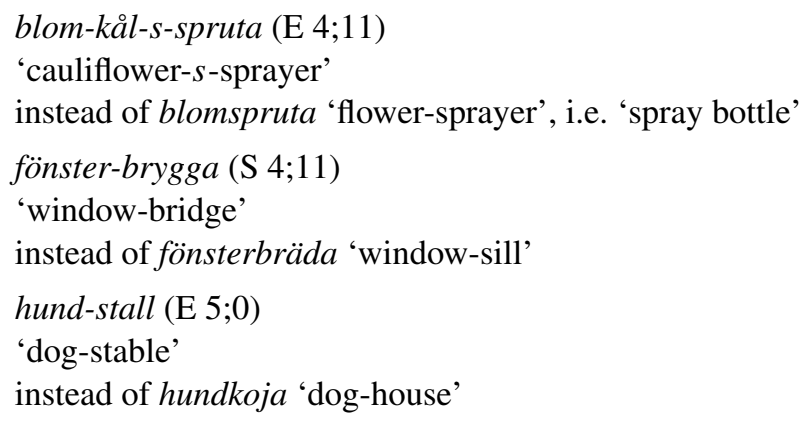

Another more complex example is the coinage in (20). Here, the semantically related sko 'shoe' is used instead of stövel 'boot' along with the phonologically related, but semantically unrelated, knäckare 'cracker' instead of knekt 'knave, jack'. Yet, the compound is still semantically sound, but with an altered etymology.

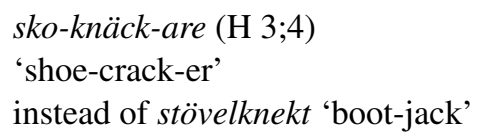

Their recreation can be based on morphological and phonological similarity with the target compound. In example (21), the stem båg- 'bow' seems to be recalled, so the child selects a lexical item he knows that contains this stem, regnbåge 'rainbow', and combines it with arm, resulting in a tripartite compound.

$$
\begin{aligned}
& \text { regn-båg }{ }_{\phi} \text {-arm-ar (E 4;6) } \\
& \text { 'rain-bow-arm-PL' } \\
& \text { instead of armbåge 'elbow' }
\end{aligned}
$$

The approximation compounds do not qualify as retrieval errors because we cannot assume that the children have stocked the established compound. Instead, the children seem to have some approximate representation of its form and try to create meaning. In this way, our data provide some evidence in support of Ngon's et al. (2013) topdown view of lexical learning as well as Elbers' (1995) output-as-input hypothesis.

Besides, something resembling the compound effect (Semenza and Mondini 2010) can be detected: in all cases, a novel compound replaces an established compound. ${ }^{9}$

\footnotetext{
${ }^{9}$ According to Libben (2014), the compound effect might have an explanation in that, during lexical processing, compound constituents add up to new lexical representations that are bound to specific positions (head vs. modifier).
} 
Hence, the children seem to know that the object to be named is named by a compound, although they miss the conventional target.

(ii) Overspecification

In the overspecified compounds, mostly produced around age three, the head that is the conventional target is combined with a superfluous noun. This overspecification leads to redundancy, and the compounds either combine two near synonyms:

$$
\begin{aligned}
& \text { spring }_{\phi} \text {-hål-en (S 3;4) } \\
& \text { 'slit-hole-PL.DEF' } \\
& \text { instead of either of the nouns } \\
& \text { (23) } \text { pann }_{\phi} \text {-gryta }(\mathrm{H} 3 ; 11) \\
& \text { 'pan-pot' } \\
& \text { instead of either of the nouns } \\
& \text { 'wind-wind' } \\
& \text { instead of either of the nouns } \\
& \text { (25) häst-släp-vagn (E 4;6) } \\
& \text { 'horse-trailer-wagon' } \\
& \text { instead of horse-trailer }
\end{aligned}
$$$$
\text { (24) blåst-vind ( } \mathrm{H} 4 ; 1)
$$

or two thematically related terms:

$$
\begin{aligned}
& \text { kort-kamera }(\mathrm{H} 3 ; 8) \\
& \text { 'photo-camera' } \\
& \text { instead of camera } \\
& \text { ko-gräs }(\mathrm{E} 3 ; 10) \\
& \text { 'cow-grass' } \\
& \text { instead of grass } \\
& \text { nyckel-lås (H 4;11) } \\
& \text { 'key-lock' } \\
& \text { instead of lock } \\
& \text { flyg-plan-s-pilot (E 5;8) } \\
& \text { 'airplane-s-pilot' } \\
& \text { instead of pilot }
\end{aligned}
$$

The overspecified compounds could be seen as supporting the principle of contrastive usage by Elbers et al. (1992), stating that words used in contrast are both different and similar in meaning (e.g. table contrasts with chair but not car). Consequently, children's use of redundancy compounds would be the reverse of filling a gap, serving instead to reduce synonymy in the lexicon. Alternatively, the competition explanation by Bowerman (e.g. 1985) according to which the child's intended meaning can simultaneously activate two synonymous or related lexical items, could come into play (cf. Elbers 1995). However, none of these explanations can account for all compounds in our data. Another option could thus be to interpret redundancy compounds as an overuse of the NN compound construction, so as to apply it also in cases where 
the ambient language does not require so. Still, it is clear that the children aim at describing the concept in a precise way, by using not only one but two related terms. By doing so, their redundancy compounds indicate a non-target-like understanding of one or both of the component nouns (e.g. if the child doesn't realize that a pilot always flies airplanes, then flygplanspilot 'airplane-s-pilot' would not be redundant).

\subsubsection{Novel compound for novel category}

Children's compounds can function to name categories that lack an established term. We discern two sub-functions depending on whether they link to a real-world referent or not: (i) detailed discrimination; (ii) reification (term borrowed from Brekle 1986).

(i) Detailed discrimination

Children can use novel compounds for categories that are not named in the ambient language. It often appears as if the children want to draw attention to a particular phenomenon by naming it and also check whether their choice of label is appropriate. On the whole, the children's detailed discriminations can be justified if considered to manifest domain expertise (cf. Jolicoeur et al. 1984).

As names for new categories, the compounds seem to arise from children's tendency to explore the world and to discriminate things in a more detailed way than adults do (cf. Clark 2004):

(30) hand-kudde (H 3;0)

'hand-pillow'

for a pillow for the hands

(31) $\quad$ flug $_{\phi}$-hål (S 3;3)

'fly-hole'

for a hole for flies

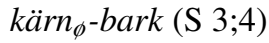

'pip-bark'

for the brown stuff left in the peach after the stone has been removed

rymd-skap-ande (E 4;6)

'space-creat-ing'

for creative work that involves outer space

(34) skog-kläder (H 4;8)

'forest-clothes'

clothes to be worn in the forest

vinter-snöre $(\mathrm{H}$ 5;0)

'winter-lace'

for a lace to be used in the winter

(36) ög-on-blind-a (E 5;2)

'eye-PL-blind-NMLZ'

for having become momentarily blind because of bright light 
hallon-labyrint (S 5;5)

'raspberry-labyrinth'

for a labyrinth made of raspberries

strå-fälla (S 5;5)

'straw-trap'

a trap made of straws

soja-mat (E 5;9)

'soya-food'

for vegetarian food

(40) marie-kex-hål-en (E 5;10)

'marie-biscuit-hole-PL'

for the tiny holes in Marie biscuits

(ii) Reification

Children's novel compounds can bring imaginary concepts into being. Indeed, children often name fantasy concepts, for example, in playing contexts. These compounds are driven by pure imagination and rely on no clearly available perceptual basis. For example, an empty ice cream package might become an emergency-room for socks (sock-akut-en, E 5;10, 'sock-emergency-DEF'). Hence, this function evidences creativity with both language and environment in a joyful game:

(41) spök-en-lukt-en (S 3;4)

'ghost-PL-smell-DEF'

for a smell of ghosts

(42) fängelse-bagare-håla (H 3;4)

'prison-baker-hole'

for a place in the prison where the baker is baking bread

(43) fotboll-s-planet-en (E 3;10)

'football- $s$-planet-DEF'

"where everyone plays football", said E

(44) stål-ben (S 4;3)

'steel-leg'

"you need a steel-leg in order to pass the sea of blood (blodhavet 'blood-seaDEF')", said S

(45) tiger-knapp (E 4;11)

'tiger-button'

"if you press the button, a tiger turns up", said E

(46) is-gaffel (H 4;11)

'ice-fork'

"those that are made of ice, you can find them in Iceland", said H

(47) virvel-dörr (H 5;0)

'swirl-door'

for a door with a swirl in it 
glädje-luft-en (H 5;0)

'joy-air-DEF'

for the air full of joy

(49) glass-ör-on (E 5;1)

ice-cream-ear-PL'

"if you eat too much ice cream, you will get ice cream-ears", said E

(50) tråd-spöke (S 5;5)

'thread-ghost'

for a tassel in a string

förvandling-s-fjäril (S 5;7)

'transformation-s-butterfly'

"this is what it would be called if some child could transform herself", said S

As the world constantly changes, so does language; new concepts are attested or invented, needing new names. Young children are also a part of this continuum, and they can detect the utility of NN compounds for this purpose.

\subsubsection{Novel compound for specific entity}

The novel compounds that pick out specific entities often express accidental relations and depend on a wider context for their interpretation. The coinages stand for a narrow concept, with little generic application. Without a shared knowledge base, it would probably be difficult to understand what entity the child aims at. The referential use, either anaphoric or deictic (Brekle's 1986 quasi-pronominal vs. deictic use), is ephemeral, but it can turn into a naming use, i.e. appropriation, which linger on and can be used out of context, once agreed upon (cf. the quote from Downing 1977 in Sect. 2.3).

(i) Anaphoric and deictic

The anaphoric compounds build upon shared, mutual knowledge deriving from some situation in the (near) past:

dum $_{\phi}$-barn-en-väg-en (S 3;3)

'mean-child-PL.DEF-road-DEF'

for a road some unknown mean children had scrawled on

björk-grej-en (E 3;10)

'birch-thing-DEF'

referring to the bird björktrast 'birch-thrush', i.e. fieldfare, which had been talked about by the child earlier in the same week when walking past some birches

(54) graffiti-barn-en $(\mathrm{H} 4 ; 0)$

'graffiti-child-PL.DEF'

for the unknown children who had painted grafitty 
peppar-kak ${ }_{\phi}$-s-bok-en (E 4;6)

'pepper-cookie-s-book-DEF'

for a book about Christmas celebration that actually did not contain a single pepparkaka 'ginger-bread' but that the child tried to describe since he wanted to read it

reklam-smör-et (S 6;6)

'commercial-butter-DEF'

for a butter of a particular brand, previously seen in a TV-commercial

The deictic compounds are strictly bound to the situation of the utterance and combine two words for objects that are accidentally juxtaposed:

melon-stol-en (H 3;7)

'melon-chair-DEF'

for a chair with a piece of melon on it

glas-ög-on-mann-en (E 3;11)

'glass-eye-PL-man-DEF'

"now, I am the eyeglasses-man" said E when he put on some eyeglasses

regn-rutschel-kana-n (S 4;4)

'rain-slide-chute-DEF'

for the playground slide when it was wet of rain

flagg $_{\phi}$-båt, prinsess $\phi_{\phi}$-båt, flyg-båt $(\mathrm{H} 4 ; 9)$

'flag-boat, princess-boat, fly-boat'

for different types of boats that were drawn and named by the child

(61) byx $x_{\phi}$-ren-hylla-n (S 5;2)

'trousers-clean-shelf-DEF'

for the shelf in the wardrobe where to put clean trousers

flug $_{\phi^{-}}$-smör (S 5;7)

'fly-butter'

uttered when there was a fly in the butter

According to Nicoladis (2003), adults are likely to understand compounds as combining two interacting objects (often inherently related), whereas children are more liberal in their compound understanding, accepting also non-interacting objects (accidentally related). Krott et al. (2010) assume that it will take children years to achieve the adult level. In a similar vein, Lynott and Connell (2010) propose a developmental trajectory of conceptual combination stipulating that young children first prefer combinations of two intact concepts (e.g. mouse hat for a hat a mouse is wearing) but progressively become able to combine potential concepts (e.g. a baby bottle does not require that a baby is present in the situation) and much-reduced concepts in combination (e.g. rabbit car for a car with rabbit ears and tail).

In our data, compounds involving two interacting objects, where one can be muchreduced or exist potentially, predominate. Less than $25 \%$ of the compounds combine juxtaposed (intact) objects. We detect no developmental path; the children prefer novel compounds for combining interacting objects from early on, but may also 
combine juxtaposed objects (e.g. (57)-(62) above). In their active production of compounds, children seem to allow things to be matched on several variables. As children combine concepts they know, they are good at meshing their affordances accurately (cf. Lynott and Connell 2010), and most of their compounds are easily interpretable in context.

The role of perception in language development is an open issue, such as the predominance given to shape in cognitive development. The "shape bias" implies that children and adults tend to extend object names based on shape similarity (Landau et al. 1988; Diesendruck and Bloom 2003). The deictic use of the children's novel compounds is sometimes based on metaphoricity, mainly concerning accidental similarity in shape (cf. Jones and Smith 2005, linking the growth of the child's productive vocabulary to the ability to represent objects by shape):

$$
\begin{aligned}
& \text { hjärt }_{\phi} \text {-potatis (H 2;11) } \\
& \text { 'heart-potato' } \\
& \text { for a potato in the shape of a heart }
\end{aligned}
$$

$$
\begin{aligned}
& \text { fling }_{\phi} \text {-berg (S 5;7) } \\
& \text { '(corn-)flake-mountain' } \\
& \text { for a pile of cornflakes } \\
& \text { pizza-hamburgare }(\mathrm{E} 5 ; 10) \\
& \text { 'pizza-hamburger' }
\end{aligned}
$$

for a piece of a hamburger that happens to have the shape of a pizza slice

Vosniadou (1987) claims that metaphoric thinking enables the child to enrich her conceptual knowledge by transferring knowledge between domains, and although children's metaphor comprehension and production emerge at preschool, these processes are not complete until late childhood. Most research on children's metaphor development concerns comprehension and/or is tested experimentally (e.g. Gottfried 1997a, 1997b). However, Gentner (1988) emphasizes the contradiction that young children perform poorly in comprehension tasks but spontaneously produce metaphors. Our data support the latter observation.

\section{(ii) Appropriation}

The children also use novel compounds to name one familiar entity. We label this use appropriation: by naming a particular object, the children single it out amongst others so as to appropriate it. Such compounds might start out as perceptually based deictic descriptions, but may remain in the speech community made up by the child's family. For example, kråkhuset (H 3;6) 'crow-house-DEF', can be used to name a particular house also when there are no crows on its roof.

On the basis of articles preceding the compounds, Clark et al. (1985) claimed that children treat compounds as labels of a category, not simply as proper names. However, our appropriation compounds are almost exclusively in the definite form, and this choice of form signals and consolidates, we claim, their status as a (proper) name: 
(66) fiske-klubb-en-tröja-n (S 3;1)

'fishing-club-DEF-sweater-DEF'

for a sweater with a print

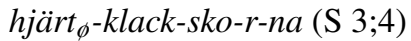

'heart-heel-shoe-PL-DEF'

for a pair of shoes with hearts

bad-kar-s-byx-or (S 3;5)

'bath-tub-s-trouser-PL'

for a pair of glittery shorts

polis-tröja-n (E 4;7)

'police-shirt-DEF'

for a shirt with police symbols printed on it

(70) skran $_{\phi}$-vant-ar (H 3;2)

'snow-slider-mitten-PL'

for the mittens to be used for snow sliding

myr $r_{\phi}$-sten-en (S 5;3)

'ant-stone-DEF'

remaining as a name for a stone that once happened to have ants creeping on it

fisk-bad-et $(\mathrm{E} 3 ; 10)$

'fish-bath-DEF'

for an inflatable pool with fish prints

In our view, appropriation compounds function as proper names for objects. Just as children pick out individuals by proper naming, they discriminate among familiar objects in their everyday life. Compounding is perfectly suited for this purpose.

Regarding the anaphoric, deictic, and appropriation compounds, an alternative for both child and adult would be to use a syntactic phrase instead (e.g. pricksockar 'dotsocks' vs. sockar med prickar på 'socks with dots on' or prickiga sockar 'dotted socks'). However, since compounds express much meaning in a condensed form, compounding could be a shortcut option. This option might be preferred by the child partly because of the perhaps greater complexity involved in producing a syntactic phrase (e.g. the choice of a correct preposition or a congruent adjective), and partly because children use language as a forum for creativity (cf. Gelman and Gottfried 2016).

\section{Concluding remarks}

This study focussed on two distinct facets of three children's novel NN compounds in Swedish: formal aspects and functions. Overall, the children's coinages were motivated and well-formed.

The analysis of formal properties revealed that their compounds respect target head order and occasionally allow for internal inflection. Around one third of their compounds would require a liaison form in order to be target-like. In more than half 
of these cases, the children used the correct target form. Given that Swedish NN compounds predominantly concatenate two nouns, the children's actual use of liaison forms reflects this frequency effect. Several nouns reoccurred either as the head or modifier in the children's compounds, and some modifier constituents were used with the correct liaison form, suggesting the emergence of constituent families. Correspondingly, children's novel compounds come with an intended meaning and combine known names for familiar objects. Producing compounds could therefore be easier for children than fully understanding compounds, whether established or novel, that derive from an external source. In compound comprehension, the child has to figure out the meanings of the constituents, their internal relation, and the meaning of the whole compound.

The function analysis suggested that the children's novel NN compounds reflected the functions that novel compounds generally have, namely as naming or referential devices (cf. Downing 1977). Moreover, the naming function-innovative wordformation par excellence-by which a novel concept was given a novel name, either seemed to arise through detailed discrimination or by bringing a fantasy concept into being. For the deictic function likewise, two sub-functions were discerned. The first of these was to refer to an entity that is either present in the situation of the utterance or bound to a situation in the past. The second sub-function was what we call the appropriation use, namely to use a novel compound to name a specific entity. In addition to the two general functions of naming and reference, the children also used novel compounds as variants of or approximations to established compounds, as well as overspecifications of simplex words, by relying on perceptual and functional features of the object to be named or on recalled phonological, morphological, and semantic cues. This last function is an indication of their lexicon being under elaboration.

As we see it, the foundational status of nouns in the developing language (Waxman et al. 2013) underpins the importance of exploring NN compounding from an early age; through compounding, children acquire deeper knowledge of objects' properties and (sub)categorization. In the wider perspective of language and conceptual development, Klibanoff and Waxman (2000) confirm earlier findings showing that familiar basic-level categories and the nouns that label them play an instrumental role in early adjective acquisition. According to Krott et al. (2009), adjective-noun (AN) phrases, with a strong preference for the IS relation (a red ball IS red), are the syntactic phrases that are the most similar to NN compounds (but cf. Rainer 2013). This interesting connection between AN phrases, AN compounds, and NN compounds in acquisition merits closer investigation.

In conclusion, this study proposes that compounding is a powerful tool for enabling children to develop their conceptual system and to build links between lexical items and constructional positions, which could reflect multiple-route processing in its early state. Compounding would thus be an advantageous strategy; children mix and match available lexical items to extend their lexicon and organize their world.

Acknowledgements The authors express their gratitude to the two anonymous reviewers, to Görel Sandström for a careful reading of the manuscript, and to Andrea Schalley for her comments on an earlier draft. 
Open Access This article is distributed under the terms of the Creative Commons Attribution 4.0 International License (http://creativecommons.org/licenses/by/4.0/), which permits unrestricted use, distribution, and reproduction in any medium, provided you give appropriate credit to the original author(s) and the source, provide a link to the Creative Commons license, and indicate if changes were made.

\section{References}

Bauer, L. (2001). Morphological productivity. Cambridge: Cambridge University Press.

Bauer, L., \& Nation, P. (1993). Word families. International Journal of Lexicography, 6(4), 253-279.

Becker, J. A. (1994). "Sneak-shoes", "sworders", and "nose-beards": a case study of lexical innovation. First Language, 14(41), 195-211.

Berman, R. A. (2009). Children's acquisition of compound constructions. In R. Lieber \& P. Štekauer (Eds.), The Oxford handbook of compounding (pp. 298-322). Oxford: Oxford University Press.

Berman, R. A. (2015). Language development and use beyond the sentence. In E. L. Bavin \& L. R. Naigles (Eds.), The Cambridge handbook of child language (2nd ed., pp. 458-480). Cambridge: Cambridge University Press.

Booij, G. (2005). The grammar of words. Oxford: Oxford University Press.

Bowerman, M. (1985). Beyond communicative adequacy: from piecemeal knowledge to an integrated system in the child's acquisition of language. In K. Nelson (Ed.), Children's language (pp. 369-398). Hillsdale: Erlbaum.

Brekle, H. E. (1986). The production and interpretation of ad hoc nominal compounds in German: a realistic approach. Acta Linguistica Academiae Scientarum Hungaricae, 36(1-4), 39-52.

Bryant, J. B. (2015). Pragmatic development. In E. L. Bavin \& L. R. Naigles (Eds.), The Cambridge handbook of child language (2nd ed., pp. 438-457). Cambridge: Cambridge University Press.

Christensen, L. (2010). Early verbs in child Swedish: a diary study on two boys. Part 1, Verb spurts and the grammar burst. Media-Tryck: Centre for Languages and Literature, Lund University.

Clark, E. V. (1981). Lexical innovations: how children learn to create new words. In W. Deutsch (Ed.), The child's construction of language (pp. 299-328). New York: Academic Press.

Clark, E. V. (2004). How language acquisition builds on cognitive development. Trends in Cognitive Sciences, 8(10), 472-478.

Clark, E. V. (2015). Lexical meaning. In E. L. Bavin \& L. R. Naigles (Eds.), The Cambridge handbook of child language (2nd ed., pp. 351-368). Cambridge: Cambridge University Press.

Clark, E. V. (2016). First language acquisition (3rd ed.). Cambridge: Cambridge University Press.

Clark, E. V., \& Berman, R. A. (1987). Types of linguistic knowledge: interpreting and producing compound nouns. Journal of Child Language, 14, 547-567.

Clark, E. V., Gelman, S. A., \& Lane, N. M. (1985). Compound nouns and category structure in young children. Child Development, 56(1), 84-94.

Corbin, D. (1987). Morphologie dérivationnelle et structuration du lexique, 2 Vol. Tübingen: Niemeyer.

Corbin, D. (1992). Hypothèses sur les frontières de la composition nominale. Cahiers de grammaire, 17, 25-55.

Costello, F. (2002). Investigating creative language: people's choice of words in the production of novel NN compounds. In W. D. Gray \& C. Schunn (Eds.), Proceedings of the 24th annual conference of the cognitive science society (pp. 232-237). Mahwah: Erlbaum.

Diesendruck, G., \& Bloom, P. (2003). How specific is the shape bias? Child Development, 74, 168-178.

Downing, P. (1977). On the creation and use of English compound nouns. Language, 53(4), 810-842.

Dressler, W. U., Kilani-Schoch, M., \& Klampfer, S. (2003). How does a child detect morphology? Evidence from production. In R. H. Baayen \& R. Schreuder (Eds.), Morphological structure in language processing (pp. 391-425). Berlin/New York: de Gruyter.

Dressler, W. U., Lettner, L. E., \& Korecky-Kröll, K. (2010). First language acquisition of compounds: with special emphasis on early German child language. In S. Scalise \& I. Vogel (Eds.), Cross-disciplinary issues in compounding (pp. 323-344). Amsterdam/Philadelphia: Benjamins

Elbers, L. (1988). New names from old words: related aspects of children's metaphors and word compounds. Journal of Child Language, 15(3), 591-617.

Elbers, L. (1995). Production as a source of input for analysis: evidence from the developmental course of a word-blend. Journal of Child Language, 22(1), 47-71.

Elbers, L., van Loon-Vervoorn, A., \& van Helden Lankhaar, M. (1992). 'Contrast' and the development of lexical organization and innovation. First Language, 12(36), 343-344. 
Elsen, H., \& Schlipphak, K. (2015). Word-formation in first language acquisition. In P. O. Müller, I. Ohnheiser, S. Olsen, \& F. Rainer (Eds.), Word-formation: an international handbook of the languages of Europe (Vol. 3, pp. 2117-2137). Berlin/Boston: de Gruyter.

Fletcher, P., \& O'Toole, C. (2016). Language development and language impairment: a problem-based introduction. Chichester: Wiley Blackwell.

Fradin, B. (2003). Nouvelles approches en morphologie. Paris: Presses Universitaires de France.

Gelman, S. A., \& Gottfried, G. M. (2016). Creativity in young children's thought. In J. C. Kaufman \& J. Baer (Eds.), Creativity and reason in cognitive development (2nd ed., pp. 9-32). Cambridge: Cambridge University Press.

Gentner, D. (1988). Metaphor as structure mapping: the relational shift. Child Development, 59, 47-59.

Gottfried, G. M. (1997a). Comprehending compounds: evidence for metaphoric skill? Journal of Child Language, 24(1), 163-186.

Gottfried, G. M. (1997b). Using metaphors as modifiers: children's production of metaphoric compounds. Journal of Child Language, 24(3), 567-601.

Jolicoeur, P., Gluck, M. A., \& Kosslyn, S. M. (1984). Pictures and names: making the connection. Cognitive Psychology, 16, 243-275.

Jones, S. S., \& Smith, L. B. (2005). Object name learning and object perception: a deficit in late talkers. Journal of Child Language, 32(1), 223-240.

Klibanoff, R. S., \& Waxman, S. R. (2000). Basic level object categories support the acquisition of novel adjectives: evidence from preschool-aged children. Child Development, 71(3), 649-659.

Koester, D. (2014). Prosody in parsing morphologically complex words: neurophysiological evidence. Cognitive Neuropsychology. Special Issue: Mental processing of compound words, 31(1-2), 147163.

Krott, A. (2009). The role of analogy for compound words. In J. Blevins \& J. Blevins (Eds.), Analogy in grammar: form and acquisition (pp. 118-136). Oxford: Oxford University Press.

Krott, A., \& Nicoladis, E. (2005). Large constituent families help children parse compounds. Journal of Child Language, 32, 139-158.

Krott, A., Gagné, C. L., \& Nicoladis, E. (2009). How the parts relate to the whole frequency effects on children's interpretation of novel compounds. Journal of Child Language, 36, 85-112.

Krott, A., Gagné, C. L., \& Nicoladis, E. (2010). Children's preference for HAS and LOCATED relations: a word learning bias for noun-noun compounds. Journal of Child Language, 37(2), 373-394.

Kuperman, V., Schreuder, R., Bertram, R., \& Baayen, R. H. (2009). Reading polymorphemic Dutch compounds: toward a multiple route model of lexical processing. Journal of Experimental Psychology: Human Perception and Performance, 35(3), 876-895.

Landau, B., Smith, L. B., \& Jones, S. S. (1988). The importance of shape in early lexical learning. Cognitive Development, 3, 299-321.

Libben, G. (2014). The nature of compounds: a psychocentric perspective. Cognitive Neuropsychology. Special Issue: Mental Processing of Compound Words, 31(1-2), 8-25.

Lynott, D., \& Connell, L. (2010). Embodied conceptual combination. Frontiers in Psychology, 1(212), $1-14$.

Lynott, D., \& Keane, M. T. (2005). Familiarity and creativity in novel compound production. In B. Bara, L. W. Barsalou, \& M. Bucciarelli (Eds.), Proceedings of the 27th annual conference of the Cognitive Science Society, Stresa, Italy (pp. 1361-1366). Mahwah: Lawrence Erlbaum.

Marelli, M., \& Luzzatti, C. (2012). Frequency effects in the processing of Italian nominal compounds: modulation of headedness and semantic transparency. Journal of Memory and Language, 66(4), 644664.

Matthews, P. H. (1974). Morphology: an introduction to the theory of word-structure. Cambridge: Cambridge University Press.

Mellenius, I. (1997). The acquisition of nominal compounding in Swedish. Doctoral dissertation. Lund: Lund University Press.

Naigles, L. R., \& Bavin, E. L. (2015). Introduction: perspectives on child language. In E. L. Bavin \& L. R. Naigles (Eds.), The Cambridge handbook of child language (2nd ed., pp. 1-12). Cambridge: Cambridge University Press.

Ngon, C., Martin, A., Dupoux, E., Cabrol, D., Dutat, M., \& Peperkamp, S. (2013). (Non)words, (non)words, (non)words: evidence for a protolexicon during the first year of life. Developmental Science, 16(1), 24-34.

Nicoladis, E. (2003). What compound nouns mean to preschool children. Brain and Language, 84(1), 38-49. 
Nicoladis, E. (2005). When level-ordering is not used in the formation of English compounds. First Language, 25(3), 331-346.

Nicoladis, E. (2007). Preschool children's acquisition of compounds. In G. Libben \& G. Jarema (Eds.), The representation and processing of compound words (pp. 96-124). Oxford: Oxford University Press.

Rainer, F. (2003). Studying restrictions on patterns of word-formation by means of the Internet. Rivista di Linguistica, 15(1), 131-139.

Rainer, F. (2013). Can relational adjectives really express any relation? An onomasiological perspective. SKASE Journal of Theoretical Linguistics, 10(1), 12-40.

Remez, R. E. (2015). Analogy and disanalogy in production and perception of speech. Language, Cognition and Neuroscience, 30(3), 273-286.

Roll, M. (2015). A neurolinguistic study of South Swedish word accents: electrical brain potentials in nouns and verbs. Nordic Journal of Linguistics, 38(2), 149-162.

Semenza, C., \& Mondini, S. (2010). Compound words in neuropsychology. Linguistiche Berichte, 17, 331-348.

Thiessen, E., \& Erickson, L. (2015). Statistical learning. In E. L. Bavin \& L. R. Naigles (Eds.), The Cambridge handbook of child language (2nd ed., pp. 37-60). Cambridge: Cambridge University Press.

Tschichold, C., \& ten Hacken, P. (2015). Word-formation in second language acquisition. In P. O. Müller, I. Ohnheiser, S. Olsen, \& F. Rainer (Eds.), Word-formation: an international handbook of the languages of Europe (Vol. 3, pp. 2137-2154). Berlin/Boston: de Gruyter.

Vosniadou, S. (1987). Children and metaphors. Child Development, 58(3), 870-885.

Waxman, S. R., Fu, X., Arunachalam, S., Leddon, E., Geraghty, K., \& Song, H. (2013). Are nouns learned before verbs? Infants provide insight into a long-standing debate. Child Development Perspectives, 7(3), 155-159.

Weisberg, R. W. (1999). Creativity and knowledge: a challenge to theories. In R. J. Sternberg (Ed.), Handbook of creativity (pp. 226-250). New York: Cambridge University Press.

Windsor, J. (1993). The functions of novel word compounds. Journal of Child Language, 20(1), 119-138. 